\title{
Role of Si on the shape memory property of Fe-Mn-Si-C based alloys
}

\author{
M. Koyama ${ }^{1}$, T. Sawaguchi ${ }^{2}$, M. Murakami ${ }^{3}$, K. Tsuzaki $^{1,2}$ \\ ${ }^{1}$ University of Tsukuba, 1-1-1 Tennoudai Tsukuba Ibaraki 305-8571, Japan \\ ${ }^{2}$ National Institute for Materials Science, 1-2-1 Sengen Tsukuba, Ibaraki 305-0047, Japan \\ 3 Shibaura Institute of Technology, 3-7-5 Toyosu Koto, Tokyo 135-8548, Japan
}

\begin{abstract}
Si content dependence of the shape memory effect (SME) associated with the $\varepsilon$-martensitic transformation has been investigated in $\mathrm{Fe}-17 \mathrm{Mn}-\mathrm{xSi}-0.3 \mathrm{C}(\mathrm{x}=0,2,4,6)$ alloys (mass\%). By conducting tensile deformations and subsequent heating to above the $A_{f}$, it has been found that reduction of mere $2 \%$ Si content from $6 \%$ to $4 \%$ obviously deteriorates the SME. The Neel and $\mathrm{M}_{\mathrm{s}}$ temperatures in both Fe-17Mn4\%Si-0.3C and Fe-17Mn6\%Si-0.3C alloys are content with the conditions concerning the good SME. By obtaining stress-strain curves at various temperatures, it has been found that the Fe$17 \mathrm{Mn}-4 \mathrm{Si}-0.3 \mathrm{C}$ alloy has similar critical stresses for $\varepsilon$-martensitic transformation and slip deformation to the critical stresses in the Fe-17Mn-6Si-0.3C alloy. As a consequence, the SME in Fe-Mn-Si-C system sometimes does not appear, even if $\varepsilon-$ martensitic transformation preferentially occurs.
\end{abstract}

\section{Introduction}

FCC $(\gamma) \rightarrow$ HCP $(\varepsilon)$ martensitic transformation occurs in a low stacking fault energy alloy. The shape memory effect (SME) in Fe-Mn-Si based alloys [1,2] arises from $\varepsilon \rightarrow \gamma$ reverse martensitic transformation. The reversibility of $\varepsilon$-martensitic transformation depends on several factors: combination of $\mathrm{M}_{\mathrm{s}}$ and Neel temperatures [3], stacking fault energy [4,5], short range ordering [6,7], strength of parent phase against permanent slip deformation[8,9] and so on. Many researchers have attempted to substitute or add elements with reference to the factors to improve the SME. Although a number of success have been reported $[10,11,12]$, the Si content is always approx. 6\% (hereinafter compositions are shown in mass\%). Tsuzaki et al. noticed that $\mathrm{Si}$ is quite effective to solution hardening, and consider that solution hardening is one of the most important key roles of Si. By comparison between alloys with and without $\mathrm{Si}$, the strength against permanent slip definitely increases by addition of $\mathrm{Si}$, which gives a new idea; addition of $\mathrm{C}$ which is also effective for solution hardening must increase the SME. As a result, an Fe-17Mn-6Si-0.3C alloy with an excellent SME was developed [8].

Assuming that the key role of $\mathrm{Si}$ is the enhancement of the strength against slip, Si content can be reduced for $\mathrm{C}$ content from the Fe-17Mn-6Si-0.3C alloy. We have investigated the Si content dependence of the strength and the SME in Fe-17Mn-xSi-0.3C alloys. The purpose of this work is to reveal the role of $\mathrm{Si}$ associated with mechanical properties, even as discuss why $6 \% \mathrm{Si}$ is necessary for the SME.

\section{Experimental}

\subsection{Sample}

Fe-17Mn-xSi-0.3C $(\mathrm{x}=0,2,4,6)$ alloys were melted in a vacuum induction furnace and ingots with $60 \mathrm{~mm} \times 60$ $\mathrm{mm} \times 120 \mathrm{~mm}$. The ingots were forged at $1273 \mathrm{~K}$ to $40 \mathrm{~mm} \times 40 \mathrm{~mm} \times 270 \mathrm{~mm}$ and hot rolled at $1273 \mathrm{~K}$ to a thickness of $15 \mathrm{~mm}$. Solution treatment was performed at $1273 \mathrm{~K}$ for $3.6 \mathrm{ks}$ in Ar followed by water quenching. The specimens for tensile tests and Dynamic Mechanical Analysis (DMA) were cut with electric spark machining. Fig. 1 shows the configuration of the tensile test sample. The specimens with dimensions of $5.0 \mathrm{~mm} \times$ $1.0 \mathrm{~mm} \times 60 \mathrm{~mm}$ were used for DMA.

This is an Open Access article distributed under the terms of the Creative Commons Attribution-Noncommercial License (http://creativecommons.org/licenses/by-nc/3.0/), which permits unrestricted use, distribution, and reproduction in any noncommercial medium, provided the original work is properly cited. 


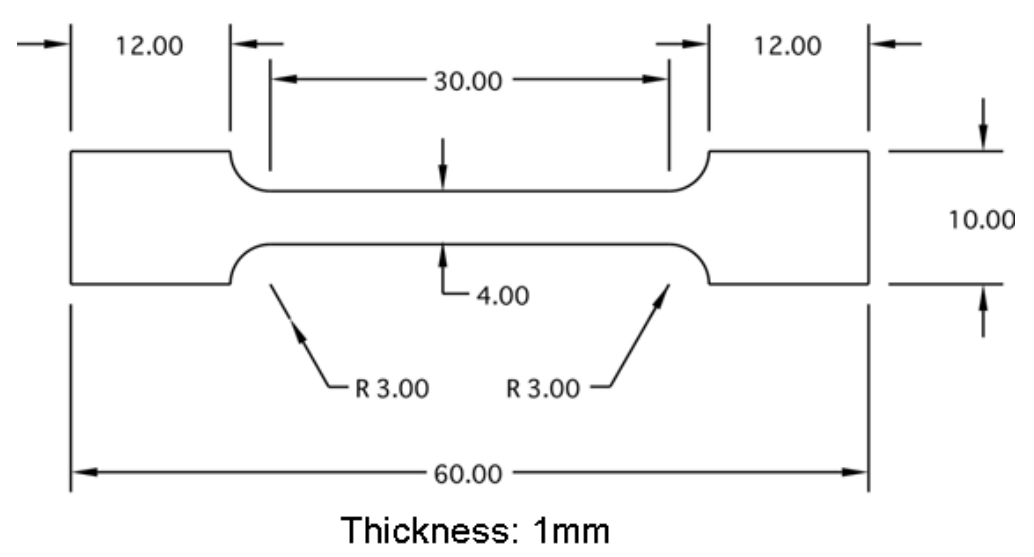

Fig.1 Configuration of the tensile test samples

\subsection{Shape memory and mechanical properties}

Shape recovery strain was measured with tensile deformations. The specimens were deformed up to proper amount of strain at a constant rate of $1.7 \times 10^{-4} \mathrm{~s}^{-1}$ using an Instron type machine. Subsequently, the specimens were heated up to $873 \mathrm{~K}$ (above $\mathrm{A}_{\mathrm{f}}$ ), and kept at $873 \mathrm{~K}$ for $10 \mathrm{~min}$. The recovery strain was calculated from a change of a gauge length; $\varepsilon_{\mathrm{r}}=\left(\mathrm{L}_{1}-\mathrm{L}_{2}\right) / \mathrm{L}_{0}$. Where $\mathrm{L}_{0}, \mathrm{~L}_{1}$, and $\mathrm{L}_{2}$ are the gauge length before the deformation, after the deformation, and after the heating, respectively.

Stress-strain curves were measured at various temperatures from $273 \mathrm{~K} \sim 523 \mathrm{~K}$ using strain gauges. In order to estimate the $0.2 \%$ proof stress against permanent slip at $294 \mathrm{~K}$, the proof stresses at temperatures from $373 \mathrm{~K}$ to $523 \mathrm{~K}$ were extrapolated to $294 \mathrm{~K}$.

\subsection{Transformation and Neel temperatures}

The $M_{s}, A_{s}$ and Neel temperatures were measured with DMA, TA instruments model 2980. Details of the determination of transformation and Neel temperatures with DMA have been reported [13,14]. In this work, we used Young's modulus obtained by the DMA measurements to determine the transformation and Neel temperatures. An example of the relationship between temperature and Young's modulus is shown in Fig.2. The specimens were austenitized by heating up to $573 \mathrm{~K}$ in the DMA before the measurements. The relationships between temperature and Young's modulus were investigated by cooling to $133 \mathrm{~K}$ and subsequent heating to 573 $\mathrm{K}$. The cooling and heating rates were $2 \mathrm{~K} / \mathrm{min}$. The amplitude and the strain amplitude were $10 \mu \mathrm{m}$ and $8.5 \times$ $10^{-5}$, and the vibration frequency was $1 \mathrm{~Hz}$.

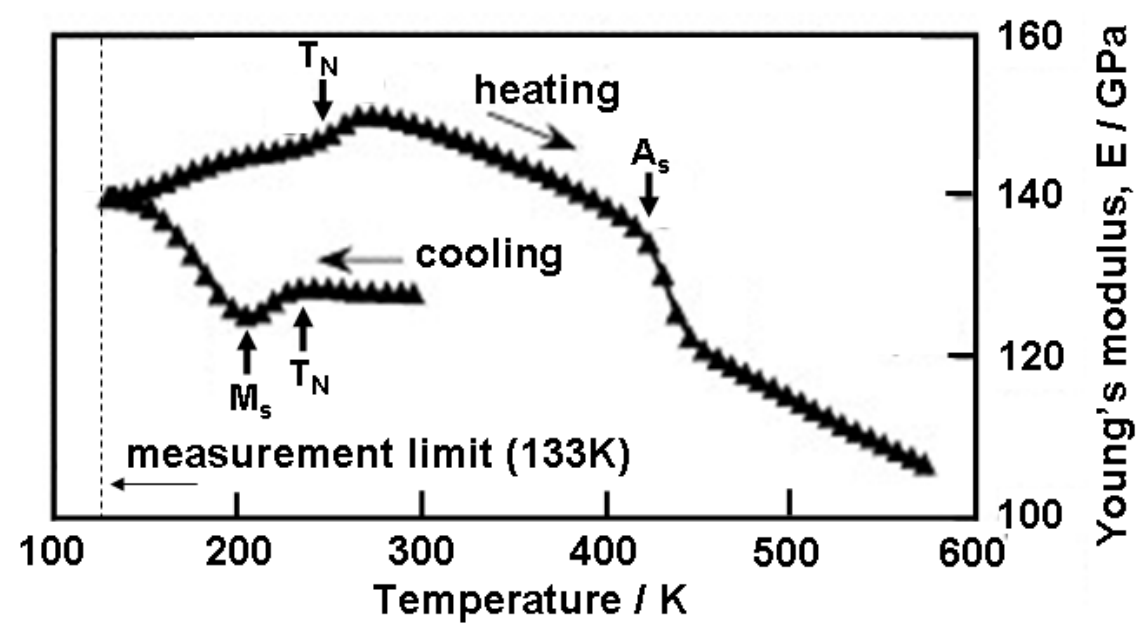

Fig. 2 The relationship between DMA data and transformation temperatures in an $\mathrm{Fe}-28 \mathrm{Mn}-6 \mathrm{Si}-5 \mathrm{Cr}-0.53 \mathrm{Nb}-$ $0.06 \mathrm{C}$ alloy $^{14)}$ 


\section{Results and discussion}

\subsection{Shape memory property and the transformation and Neel temperatures}

Shown in Fig. 3 is the relationship between $\mathrm{Si}$ concentration and recovery strain. The 4\% initial strain was given by tensile deformation at room temperature. The accurate values of the initial strain are $4.47 \%, 4.35 \%$, $4.32 \%$ and $4.22 \%$ for $0 \% \mathrm{Si}, 2 \% \mathrm{Si}, 4 \% \mathrm{Si}$ and $6 \% \mathrm{Si}$ alloys, respectively. Notice that the recovery strain leads to a large increase in addition of $6 \% \mathrm{Si}$. Contrary to our hypothesis; $\mathrm{Si}$ content can be reduced for $\mathrm{C}$ content, the result indicated that $4 \% \mathrm{Si}$ does not have good SME. This raises the question of how $6 \% \mathrm{Si}$ affects the SME. In this paper, I will concentrate on the following issues to settle the question: the relationship between transformation and Neel temperatures and solution hardening. Si concentration dependence of Neel temperature is shown in Table 1 and Fig.4. We could not obtain the $\mathrm{T}_{\mathrm{N}}$ of $6 \% \mathrm{Si}$ because of measurement limit in the DMA. The measurement limit for a low temperature side is $133 \mathrm{~K}$. Where $\mathrm{T}_{\mathrm{N}}$ lies above $\mathrm{M}_{\mathrm{s}}$, a SME is deteriorated because of the stabilization of austenite due to antiferromagnetic ordering. Although $2 \% \mathrm{Si}$ and $4 \% \mathrm{Si}$ have $\mathrm{T}_{\mathrm{N}}$ below $\mathrm{M}_{\mathrm{s}}$, the recovery strain is poor compared with $6 \% \mathrm{Si}$. Namely, as far as the $\mathrm{SME}$ in $2 \% \mathrm{Si}, 4 \mathrm{Si}$ and $6 \mathrm{Si}$ is concerned, we can rule out the effect of Neel temperature. Ms and As temperatures for $0 \sim 6 \% \mathrm{Si}$ alloys were clearly shown in DMA results, indicating that $\varepsilon$-martensitic transformation definitely occurs in the all alloys.

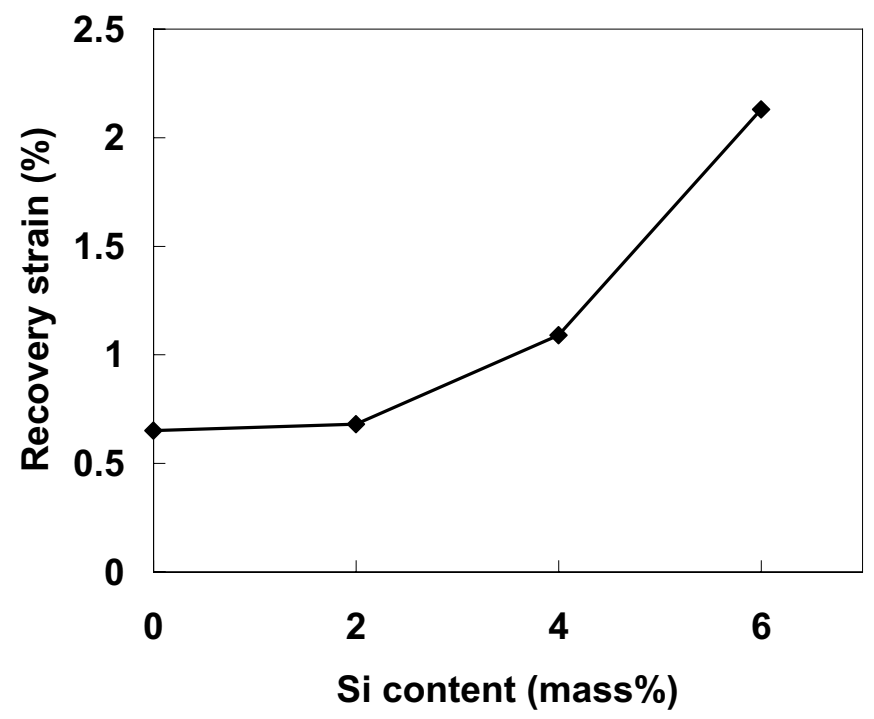

Fig. 3 Recovery strain versus Si content in Fe-17Mn-xSi-0.3C alloys. The initial strain was approx. 4\%, and the recovery strain was obtained by heating at $873 \mathrm{~K}$.

Table $1 \mathrm{M}_{\mathrm{s}}$ and $\mathrm{A}_{\mathrm{s}}$ martensitic transformation temperatures along with Neel temperature

\begin{tabular}{|c|c|c|c|}
\hline Alloy (mass\%) & $\mathrm{M}_{\mathrm{s}}$ & $\mathrm{A}_{\mathrm{s}}$ & Neel \\
\hline Fe-17Mn-0Si-0.3C & $272 \mathrm{~K}$ & $463 \mathrm{~K}$ & $315 \mathrm{~K}$ \\
\hline Fe-17Mn-2Si-0.3C & $301 \mathrm{~K}$ & $474 \mathrm{~K}$ & $254 \mathrm{~K}$ \\
\hline Fe-17Mn-4Si-0.3C & $307 \mathrm{~K}$ & $490 \mathrm{~K}$ & $203 \mathrm{~K}$ \\
\hline Fe-17Mn-6Si-0.3C & $275 \mathrm{~K}$ & $485 \mathrm{~K}$ & $<133 \mathrm{~K}$ \\
\hline
\end{tabular}




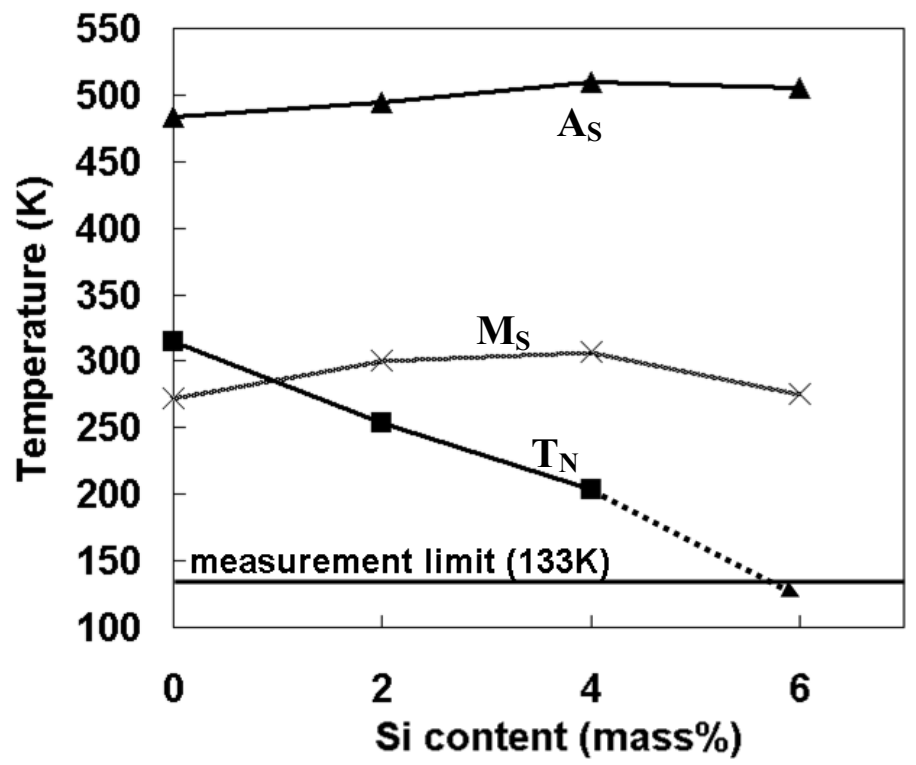

Fig. $4 \mathrm{Si}$ content dependence of transformation and Neel temperatures

\subsection{Mechanical properties}

Table 2 and Fig. 5 show the effect of silicon on the difference between the critical stresses for $\varepsilon$-martensitic transformation and slip deformation at room temperature. We regarded the $0.2 \%$ proof stresses at room temperature as the critical stresses for $\varepsilon$-martensitic transformation. Although the critical stress for $\varepsilon$-martensitic transformation and slip deformation increase with the increase of $\mathrm{Si}$ content until $4 \% \mathrm{Si}$, the critical stress for $\varepsilon$ martensitic transformation and slip deformation of $4 \% \mathrm{Si}$ and $6 \% \mathrm{Si}$ are almost same. In addition, It was pointed out in the previous section that the recovery strain of $4 \% \mathrm{Si}$ is unsatisfactory compared with $6 \% \mathrm{Si}$. The results clearly show that recovery strain is not always good, even if the strength against slip is sufficiently-high.

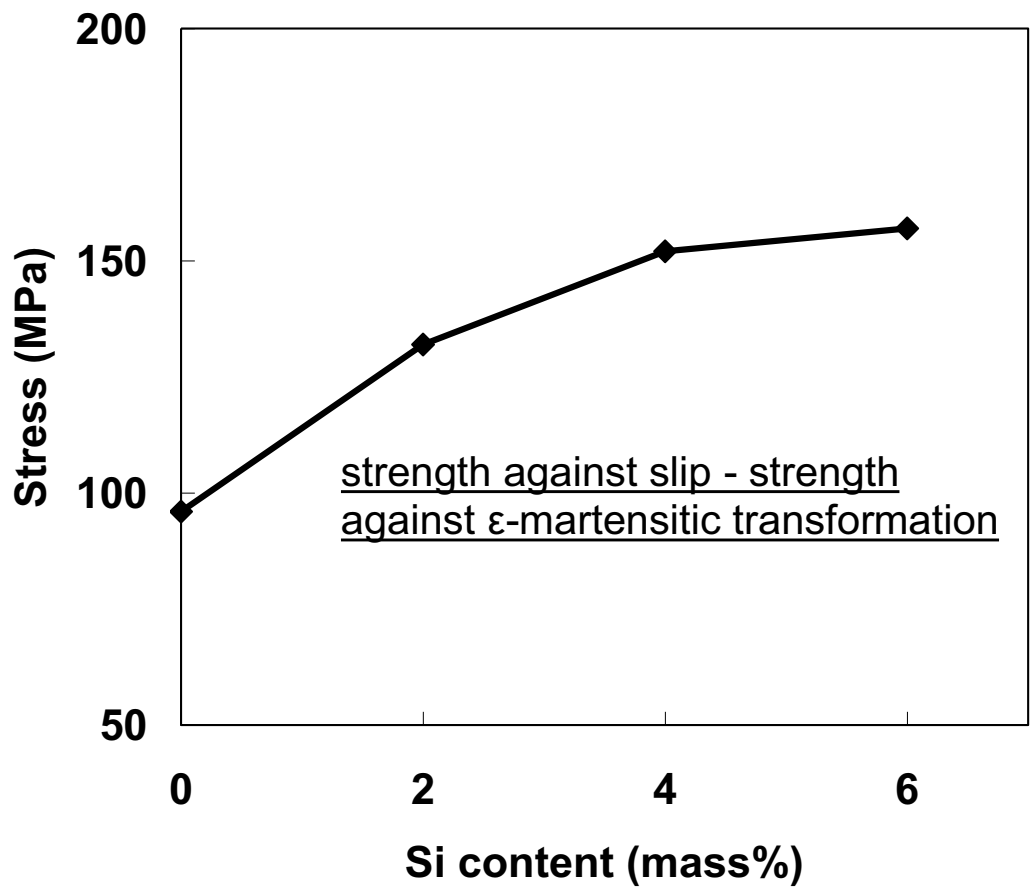

Fig.5 $\triangle \sigma_{\mathrm{y}}$ versus $\mathrm{Si}$ content in Fe-17Mn-xSi-0.3C alloys 
Table 2 Si content dependence of the critical stresses for $\varepsilon$-martensitic transformation, $\sigma_{\mathrm{y}}(\gamma \rightarrow \varepsilon)$, and slip deformation, $\sigma_{\mathrm{y}}\left(\gamma\right.$ slip), and their difference, $\Delta \sigma_{\mathrm{y}}$, at room temperature. $\Delta \sigma_{\mathrm{y}=\sigma_{\mathrm{y}}}(\gamma$ slip $)-\sigma_{\mathrm{y}}(\gamma \rightarrow \varepsilon)$

\begin{tabular}{|c|c|c|c|}
\hline Alloy $($ mass $\%)$ & $\sigma_{\mathrm{y}}(\gamma \rightarrow \varepsilon)$ & $\sigma_{\mathrm{y}}(\gamma$ slip $)$ & $\Delta \sigma_{\mathrm{y}}$ \\
\hline Fe-17Mn-0Si-0.3C & $188 \mathrm{MPa}$ & $289 \mathrm{MPa}$ & $101 \mathrm{MPa}$ \\
\hline Fe-17Mn-2Si-0.3C & $205 \mathrm{MPa}$ & $337 \mathrm{MPa}$ & $132 \mathrm{MPa}$ \\
\hline Fe-17Mn-4Si-0.3C & $214 \mathrm{MPa}$ & $366 \mathrm{MPa}$ & $152 \mathrm{MPa}$ \\
\hline Fe-17Mn-6Si-0.3C & $205 \mathrm{MPa}$ & $362 \mathrm{MPa}$ & $157 \mathrm{MPa}$ \\
\hline
\end{tabular}

\section{Summary}

The effect of Si addition on the shape memory property associated with $\varepsilon$-martensitic transformation has been examined in $\mathrm{Fe}-17 \mathrm{Mn}-\mathrm{xSi}-0.3 \mathrm{C}$ alloys. It is clearly shown that the shape memory property requires $6 \% \mathrm{Si}$. By comparison of some parameters in Fe-17Mn-xSi-0.3C alloys, it has been found that the increase of Si content linearly decreases the Neel temperature but does not affect the $M_{s}$ temperature. The condition of the $M_{s}$ and Neel temperatures of Fe-17Mn-2Si-0.3C, Fe-17Mn-4Si-0.3C and Fe-17Mn-6Si-0.3C alloys are satisfied for the shape memory effect. Moreover, by analyzing the critical stresses for $\varepsilon$-martensitic transformation and slip deformation in Fe-17Mn-4Si-0.3C and Fe-17Mn-6Si-0.3C alloys, it is suggested that good shape recovery, given sufficient enhancement of strength against permanent slip, is sometimes possible. It is also true that in some cases good shape recovery does not appear in spite of the high strength against permanent slip such as the Fe-17Mn- $4 \mathrm{Si}$ $0.3 \mathrm{C}$ alloy.

The present work was supported by Japan Science and Technology agency (JST).

\section{References}

[1]A. Sato, E. Chishima, K. Soma and T. Mori: Acta. metal. 30 (1982) 1177-1183

[2] M. Murakami, H. Otsuka, H.G. Suzuki and S. Matsuda: Proc. ICOMAT (1986) 985-990

[3] M. Murakami, H. Otsuka, H. Suzuki and S. Matsuda: Trans. ISIJ 27 (1987 B-88

[4] Y.K. Lee and C.S. Choi: Metall. Mater. Trans. A 31A (2000) 355-360

[5] B. Jiang, X. Qi, S. Yang, W. Zhou and T.Y. Hsu: Acta mater. 46 (1998) 501-510

[6] M. Sade, K. Halter and E. Hornbogen: Z. Metall. 79 (1988) 487-491

[7] V.V Bliznuk, V.G. Gavriljuk, G.P. Kopitsa, S.V. Grigoriev and V.V. Runov: Acta Mater. 52 (2004) 47914799

[8] K. Tsuzaki, Y. Natsume, Y. Kurokawa and T. Maki: Scr. Metall et Mater. 27 (1992) 471-473

[9] K. Tsuzakl, Y. Natsume, Y. Tomota and T. Maki: Scr. Metall. et Mater. 33 (1995) 1087-1092

[10] H. Otsuka, H. Yamada, T. Maruyama, H. Tanahashi, S. Matsuda and M. Murakami: ISIJ int. 30 (1990) 674679

[11] S. Kajiwara, D. Liu, T. Kikuchi and N. Shinya: Scr. mater. 44 (2001) 2809-2814

[12] H. Kubo, K. Nakamura, S. Farjami and T. Maruyama: Mater. Sci. Eng. A 378 (2004) 343-348

[13] F.X. YIN, S. Takamori, Y. Ohsawa, A. Sato and K. Kawahara: Mater. Trans. 43 (2002) 466-469

[14]Z. Dong, T. Sawaguchi, T. Kikuchi, F. Yin, K. Ogawa, P. Sahu and S. Kajiwara: Mater. Sci. Eng. A 442

(2006) 404-408 